Research Article

\title{
Sensor Placement Strategies for the Seismic Monitoring of Complex Vaulted Structures of the Modern Architectural Heritage
}

\author{
Erica Lenticchia (D), Rosario Ceravolo $(\mathbb{D}$, and Paola Antonaci \\ Department of Structural, Geotechnical and Building Engineering, Politecnico di Torino, Corso Duca degli Abruzzi 24, \\ 10129 Turin, Italy
}

Correspondence should be addressed to Rosario Ceravolo; rosario.ceravolo@polito.it

Received 28 March 2018; Accepted 28 June 2018; Published 1 August 2018

Academic Editor: Emanuele Reccia

Copyright ( 2018 Erica Lenticchia et al. This is an open access article distributed under the Creative Commons Attribution License, which permits unrestricted use, distribution, and reproduction in any medium, provided the original work is properly cited.

Effective diagnostic and monitoring systems are highly needed in the building and infrastructure sector, to provide a comprehensive assessment of the structural health state and improve the maintenance and restoration planning. Vibration-based techniques, and especially ambient vibration testing, have proved to be particularly suitable for both periodic and continuous monitoring of existing structures. As a general requirement, permanent systems must include a sensing network able to run a continuous surveillance and provide reliable analyses based on different information sources. The variability in the environmental and operating conditions needs to be accounted for in designing such a sensor network, but it is mainly the structural typology that governs the optimal sensor placement strategy. Architectural heritage consists of a great variety of buildings and monuments that significantly differ from each other in terms of typology, historic period, construction techniques, and materials. In this paper, the main issues regarding seismic protection and analysis of the modern architectural heritage are introduced and applied to one of the vaulted structures built by Pier Luigi Nervi in the Turin Exhibition Centre. The importance of attaining an adequate level of knowledge in historic structures is also highlighted. After an overview of the Turin Exhibition Centre and its construction innovations, this paper focuses on Hall B, describing the structural design conceived by Pier Luigi Nervi. A seismic assessment of the structures of Hall B is then presented, considering the potential seismic damage to nonstructural elements. Subsequently, the application of an optimal sensor placement strategy is described with reference to two different scenarios: the first one corresponding to the undamaged structure and the second one that considers a possible damage to the infill walls. Finally, a novel damage-scenario-driven sensor placement strategy based on a combination of the two above mentioned is proposed and discussed. One of the major conclusions drawn from the analyses performed is that nonstructural elements undergoing seismic damage or degradation may significantly affect the global dynamic response and consequently the optimal sensing configurations.

\section{Introduction}

Optimal sensor placement techniques play a significant role in assuring a reliable positioning of sensors for Structural Health Monitoring (SHM). This is particularly true in the case of complex systems or configurations, in which a large number of possible positions and degree of freedoms are present. In the case of architectural heritage, these issues are even more relevant due to the uncertainties of the building construction technologies and the diversity of architectural configurations. These uncertainties entail significant complexities in the design of a possible dynamic monitoring system. Indeed, architectural heritage consists of a great variety of buildings and monuments, which differ from each other in terms of typology, historic period, construction techniques, and materials and very often are characterized by the occurrence in time of several changes in the structural design and in the end use. The architectural heritage of the modern movement makes no exception, and its conservation is perhaps one of the most controversial frontiers in the field of architectural preservation. Presently, much of the world's heritage from this period is unrecognized or undervalued, and therefore, it is at risk and in need of analysis and protection. This vulnerable situation can be attributed to 
multiple factors: 20th century buildings still struggle to be considered part of a heritage; moreover, their original functions have substantially changed, and their technological innovations have not always endured long-term stresses.

Vibration-based structural health monitoring techniques for the control and diagnosis of structures have been applied for years and have now become an important tool for the preservation of either antique or modern architectural heritage $[1,2]$. Dynamic tests are particularly appreciated in this field because they are a nondestructive technique and provide information about the whole-body response of the structure and its overall structural integrity.

However, the dynamic monitoring of architectural heritage structures still raises different unresolved issues, including (i) the complex optimisation problems due to the spatial characters of architectural heritage; (ii) the need for distributed sensing systems with corresponding optimisation of their configurations; and (iii) the possible effects of damage degradation on the sensing system's design.

Based on the above-reported considerations, in this paper, an iconic structure of modern architectural heritage was analysed, that is, the Turin Exhibition Centre, designed and built by Pier Luigi Nervi. Its halls, with their vaulted roofing systems, represent a structural masterpiece of the period and are admired worldwide for their challenging and innovative conception.

Despite its remarkable historical and architectural relevance, the Turin Exhibition Centre has been abandoned for a long time, and the lack of maintenance is starting to induce serious preservation problems. In addition, its halls were built without accounting for seismic actions, but only for static configurations, in accordance with the technical standards of the time. Therefore, it is of crucial importance to assess the dynamic behaviour of these structures in order to understand their vulnerability and plan their correct preservation measures. These structures represent a challenging example, especially in view of defining their optimal sensor configurations.

Numerical simulations under different damage scenarios were conducted, in order to evaluate the influence of nonstructural elements, such as the infill walls, on the behaviour of the building and thus on the optimal sensor placement. In fact, sensor placement strategy, in such complex structures, has to consider also the effect of possible damage in nonstructural elements. Therefore, in this study, the objective function of the algorithm was modified in order to account for progressive damage in the infill walls. The numerical analyses demonstrated that these elements, when subjected to seismic damage or degradation, may significantly affect the global dynamic response and consequently the optimal monitoring configurations.

\section{Optimal Sensor Placement}

2.1. Optimisation Algorithms for Optimal Sensor Placement. When designing a SHM system, it is necessary to first perform an accurate analysis of the structural behaviour, in order to select the most significant and sensitive parameters. One of the most critical issues in the design of a dynamic monitoring system is the deployment of the sensors, usually in the form of accelerometers, especially when testing complex structures. In fact, in the case of structures that present a simple geometry, the optimal location of sensors can be considered a trivial problem that can be solved by simply relying to the experience of the operator. On the contrary, in the case of complex structures, as it often happens with architectural heritage, it is recommended to recur to more sophisticated strategies, such as optimal sensor placement (OSP) [3].

Optimal sensor placement techniques play a significant role in enhancing the quality of modal data in SHM. This is particularly true for large civil structures, where a limited number of sensors are normally available to monitor a huge number of movements. The accelerometers must be placed in order to obtain all the relevant features of the dynamic response during the course of the test, and, at the same time, the resulting sensor configuration must be optimal such that testing resources are conserved [4].

The problem of locating sensors on a structure can be driven by the aim of maximising the data information in order to fully characterize the structural dynamic behaviour. In this case, the primary objective is the enhancement of the modal testing results. Several studies have been carried out to cope with this problem using the a priori information derived by a FE model of the structure.

Although many different sensor placement algorithms can be implemented to optimise the number and location of sensors on the structure, a general common criterion of information maximisation is recognizable. The knowledge of the expected type of damage represents an important discriminating element. If the purpose is fault detection and classification, the problem of determining the best number of sensors and their locations is mainly an optimisation problem. Recently some optimisation methods based on analogies with biology and physics have been introduced. Artificial Neural Networks (ANNs), Pattern Search (PS), and Evolutionary Strategies (ES), such as the Genetic Algorithms (GA) [5], the Particle Swarm Optimization (PSO) [6], and the Covariance-Matrix Adaptation Evolution Strategy (CMA-ES), are only some of the countless examples present in the literature [7].

A popular OSP approach is the one proposed by Kammer [8] and consists in a minimisation of the norm of the Fisher information matrix. The method of Effective Independence (EI) was developed to assure the spatial independence and to maximise the signal strength of a certain number of targeted mode shapes. The algorithm is iterative: at each step, as the lowest ranked sensor is removed, the determinant of the Fisher information matrix is maintained, resulting in a suboptimal optimisation which ends when the required number of sensors is obtained.

Another way to solve the problem is the modal kinetic energy-based method as proposed by Salama et al. [9] and Chung and Moore [10] as a means of ranking the importance of candidate sensor locations. The Kinetic Energy Method (KEM) looks for the sensor placement configuration whose positions are the points of maximum kinetic energy for the modes of interest in order to maximise their observability. 
The procedure to derive the best sensors positions is similar to that implemented in the EI method with the difference that the Fisher information matrix is substituted by the KE matrix.

A third approach that uses the mass-to-stiffness ratio associated with each candidate sensor location was proposed by [11]. A more detailed review of OSP methods with particular emphasis on vibration measurements can be found in [12-15].

In the aforementioned methods, the definition of a certain number of target mode shapes is required. This number can be selected as the number of modes which are expected to be identified by the modal testing. Finally, it must also be stressed that due to economic considerations, the number of available sensors is generally limited and sometimes even insufficient to fulfil the requirements of the optimal sensor placement techniques.

In order to overcome this limit, it is common to use different overlaying setups during a dynamic testing campaign. The identified measuring positions are split into two groups: the points belonging to the first group are assumed as reference and kept fixed in every acquisition carried out on the structure, and the other points are moved around the structure defining a number of setups sufficient to investigate all the identified locations $[3,16]$. The positions selected as reference points should correspond to the points which undergo the largest modal displacements and definitely not coincide with the nodes of the structural mode shapes.

2.2. Genetic Algorithms for OSP. A special family of optimisation strategies for OSP relies on the use of Genetic Algorithms (GAs), offering simple and robust criteria for the solution of the problem of optimal placement of accelerometers.

GAs are a popular bioinspired approach, with many examples of their use appearing in the engineering literature [17], as their use is known to reduce the probability to incur in local minima. According to [12], the first pioneering studies on using GAs for the sensor placement problems date back to the early nineties [18]. For the exposed reasons, and due to their simplicity, GAs are highly recommended also in the case of complex civil structures and, in fact, were chosen to define the OSP for the vaulted halls in the Turin Exhibition Centre.

GAs are optimisation algorithms which evolve solutions in a manner analogous to the Darwinian principle of natural selection, where members of the population compete to survive and reproduce while the weaker ones die out [19]. Each individual is assigned a fitness value according to how well it meets the objective of solving the problem and, in this paper, to identify the optimal position of the sensors. Each possible solution, that is, each set of possible parameters in solution space, is encoded as a gene. Having decided on a representation, the next step is to randomly generate an initial population of possible solutions. The number of genes in a population depends on several factors, including the size of each individual gene, which itself depends on the size of the solution space [12].

Having generated a population of random genes (the accelerometers), it is necessary to decide which of them are fittest in the sense of producing the best solutions to the problem (the vibration modes discerning). To do this, a fitness function is required which operates on the encoded genes and returns a single number which provides a measure of the suitability of the solution. These fittest genes will be used for mating to create the next generation of genes which will hopefully provide better solutions to the problem. Genes are picked for mating based on their fitness. The probability of a particular gene to be chosen is equal to its fitness divided by the sum of the fitnesses of all the genes in the population [12]. Once a sufficient number of genes have been selected for mating, they are paired up randomly, and their genes are combined to produce a new couple of genes. The most common method of combination used is called crossover.

With genetic methods, it is not always possible to say what the fitness of a perfect gene will be [12]. Thus, the iterative process is usually continued until the population is dominated by a few relatively fit genes. One or more of these genes will generally be acceptable as solutions.

The objective function used in the optimisation problem here analysed is based on the concept of Modal Assurance Criterion (MAC) [20, 21], a matrix containing element indices of the correspondence of two modal vectors. In fact, the elements of the matrix can take values between 0 , which indicates vectors devoid of correlation, and 1 , which indicates equal vectors. The generic term of MAC can be defined as

$$
\mathrm{MAC}_{i j}=\frac{\left(v_{i}^{T} v_{j}\right)^{2}}{\left(v_{i}^{T} v_{i}\right)\left(v_{j}^{T} v_{j}\right)},
$$

where $v_{i}$ and $v_{j}$ are, respectively, the $i$ th and $j$ th column of matrix $v$, which is the reduced modal matrix of the degrees of freedom corresponding to possible measurement positions.

The goal of the OSP is to minimise the elements outside the diagonal of the MAC matrix. The genetic algorithm searches for the best set of positions that allow to minimise each term MACij $(i \neq j)$. This allows to distinguish the modes to be monitored on the basis of a given number of accelerometers. The objective function used to solve the problem of the OSP is based on the above-stated definitions, as it derives from the simple subtraction of terms related to the MAC calculated using the modal matrix (MAC_R) with those of the ideal MAC (MAC_I) and divided by the number of the elements of the matrix with selected target modes extracted from the FE model:

$$
\text { error }=\frac{\sum_{i} \sum_{j}(\text { MAC_R }- \text { MAC_I })}{n},
$$

where (2) represents the objective function to be minimised and $n$ is the number of elements of the matrix.

The above-referred OSP strategy will be hereinafter applied to determine the best sensor locations from a large set of possible candidates in Hall B of Turin Exhibition Centre. 


\section{Finite Element Modelling and Analysis}

3.1. The Turin Exhibition Centre. As stated in the introduction, in recent years, there has been an increase in the recognition of the cultural significance of modern architecture. However, there are still challenges to secure its protection and conservation $[22,23]$. An area of conservation that requires attention is seismic provision. In fact, modern architecture buildings were designed and built with no, or very limited, seismic provisions, due to the lack of reference technical standards at the time of their construction. With a view to the restoration and renewal of these complex structures, a careful assessment of their structural performance is a priority, especially when they are situated in a high seismic risk area.

Pier Luigi Nervi (1891-1979) was one of the greatest and most inventive structural engineers of the 20th century [24]. With his masterpieces, Nervi contributed to create a glorious period for structural architecture [25]. Nikolaus Pevsner, the distinguished historian of architecture, described him as "the most brilliant artist in reinforced concrete of our time" [26]. Between the thirties and the sixties, structural research, particularly into thin concrete shells for vaulted structures, achieved extraordinary results. Dating back from the thirties, thin-shell roofs in concrete were seen as "the starting point for the specific solution of the vaulting problems" [27], and vaulting forms were created taking inspiration by simple ideas grounded in the laws of nature [28] both empirically and mathematically. Researchers and designers of the time adopted a highly pragmatic approach to the industrialisation of construction systems, optimal use of materials, and structural analysis [29]. Pier Luigi Nervi was one of the leading structural designers of the period together with Eduardo Torroja, Anton Tedesko, and Nicolas Esquillan and many others. The vaulted structures in the Turin Exhibition Centre are among many spatial buildings that were built at the time.

For Pier Luigi Nervi, the Turin Exhibition represented the first possibility to apply the principle of structural prefabrication, combining with a single large-scale vaulted structure his patented ferrocement technique with the extensive use of prefabricated elements. This combined use of two different technologies for the construction of large concrete shells became later one of the distinctive traits of Nervi's work.

In the construction of both halls of the Turin Exhibition Centre, Nervi used new construction procedures that he studied for some years before this project. In fact, he had already successfully used these procedures with his engineering firm Nervi and Bartoli, even on smaller experimental buildings, such as the small storehouse in the Magliana area in Rome (1946) [30], the wharf Conte Trossi in San Michele di Pagana (1947), and the ceiling of the pavilion at the Milan Fair (1947) [31].

The Turin Exhibition Centre (Palazzo di Torino Esposizioni) was built in 1948 for the 31st international Auto Show. The tender was committed to Nervi and Bartoli, whose project proposed a new construction system that combined prefabrication and the use of ferrocement. The building consists of the main Hall B and the smaller adjacent
Hall C [32], both designed and constructed by Nervi (19471948 and 1950). A historical aerial view of the building is reported in Figure 1.

3.2. The Vaulted Structures of Hall B. Hall B was inaugurated on 15 September 1948. Conceived like a cathedral, the hall consists of a nave covered by an undulated thin vault and of an apse with a ribbed hemispherical dome. Figure 2 shows a plan of the complex, with Hall B coloured in red (Figure 2(a)) and a detail of the ribbed apse (Figure 2(b)). In its first configuration, Hall $B$ measured 96 metres in width and 110 metres in length. Between 1952 and 1954, Hall B was enlarged by five spans in order to move the facade on the street. Hall B reached the length of 155 metres (Figure 3).

For the covering of the large hall, Nervi decided to build a thin-shell vault with large undulations, using precast elements built in ferrocement that was preferred for its lightweight and its resistance. For the vault, Nervi studied special wave-like elements in prefabricated ferrocement. The centre line of the arched vault of Hall B approaches the funicular of permanent loads and is formed by the union for each arch of the 13 prefabricated thin ferrocement undulated elements of approximately $4.5 \mathrm{~m}$ weighing $1500 \mathrm{~kg}$ each. Their ends are stiffened by diaphragms that leave an empty space of $4 \mathrm{~cm}$ to be filled with cement mortar. These waved elements were patented in August 1948 just before the inauguration of Hall B (patent no: 445781) [35]. The idea was to shape the prefab elements using a geometry that would guarantee a high moment of inertia with a minimum amount of material [36]. The problem of obtaining a true static collaboration of the precast elements was resolved by casting in place a concrete rib on both the top and the bottom of the undulations. These ribs were large enough to resist the principal stresses, while the sides of the precast elements assured the static tie between the ribs and reestablished the monolithic nature of the whole [33, 37]. At the end point of the individual corrugations, Nervi designed a transitional element that matched the profile of three adjacent corrugations to that of a reinforced concrete pier below [38]. The transitional element thus became a fan-like shape in which the undulated elements above were traced through a narrowing section until they disappeared into the width and depth of the pier below [31].

The apsidal semidome was instead constructed in small, lozenge-shaped prefabricated ferrocement tiles, used as permanent formwork. They were connected by reinforced concrete cast on-site in the lateral ribs and on their tops and are similar to the roof of the ribbed pavilion resting on four inclined arches of the successive and adjacent Hall C (194950). In the case of Hall $\mathrm{B}$, the ring at the base of the halfdome has to absorb the unsymmetrical forces. This action is entrusted to the perimetral slab.

As it has emerged from the preliminary knowledge phase, Hall B is a very complex building (see Figure 4 for a $3 \mathrm{D}$ representation). The building is composed by a large number of elements, 390 precasted ferrocement pans in seven different depths [31], slanted pillars, and innovative solutions like the fanned elements, that Nervi designed to 


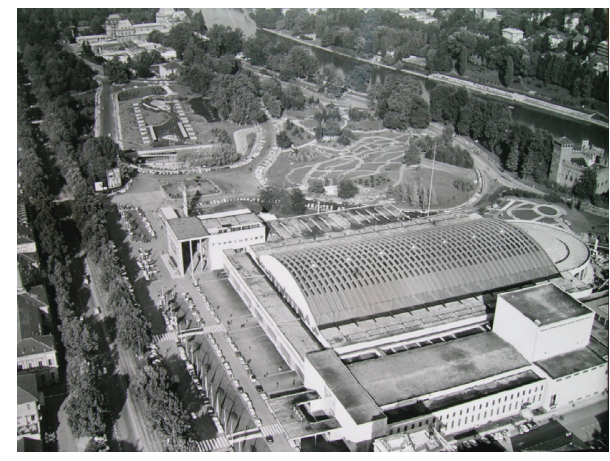

Figure 1: Aerial view of the Turin Exhibition Centre: the large hall with the semicircular apse is Hall B built in 1948.

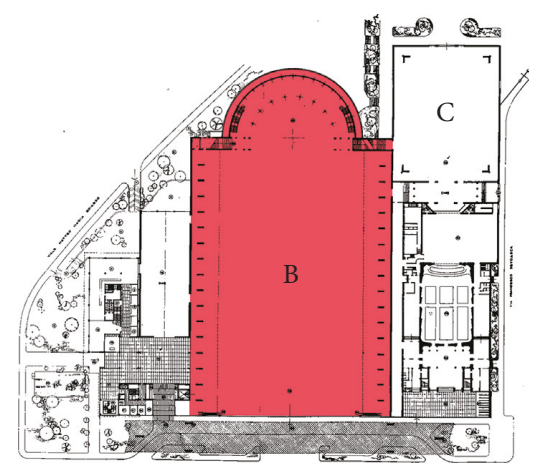

(a)

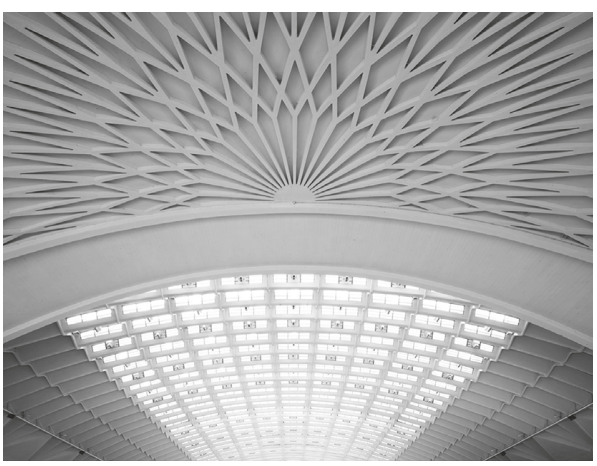

(b)

Figure 2: (a) Turin Exhibition Centre plan: the large hall with the semicircular apse is Hall B built in 1948 B [33]. (b) An interior of Hall B showing the detail of joint between the ribbed half-dome and the undulated vault.

condense loads from lightweight, folded plate roofs into the piers [38].

3.3. Modelling and Analysis of Hall B. The finite element models (FEM) of Hall B were constructed on the basis of all the significant data that were gathered from the original drawings and calculation report, made by Pier Luigi Nervi, which are stored in the Centro Studi e Archivio della Comunicazione (CSAC) of Parma [39]. This documentation provided the geometric and dimensional characteristics of the structure for the hall, as well as the classification of the elements and the materials employed. The historical analysis allowed a better understanding of the constructive evolution of the building as well as its structural conception. A critical review of the drawings was fundamental in order to build the geometrical model, especially in consideration of the difficulties in identifying the pertinent design phase (preliminary, definitive, or final), that often happens when analysing an historical building [40]. The simplified geometric models were subsequently used for the construction of the FE models [41]. At this stage of the analysis, linear models were preferred, also due to the lack of experimental data on material properties. They will be described in detail in the next subsections.

From a spatial and structural conception point of view, it can be said that Hall B is composed by two different spaces: the vaulted undulated hall and the half-dome. The two spaces are linked by a tympanum and a vault in reinforced concrete, lightened by masonry blocks (patent name: SAP) [42].

The ribs of the half-dome were modelled with a linear (2node) beam element in 3D with six degrees of freedom at each node. The degrees of freedom at each node include translations in $x, y$, and $z$ directions and rotations about the $x, y$, and $z$ directions. The ferrocement filling slabs, the undulated elements of the thin-shell vault, the various slabs, and the slanted piers were modelled with bidimensional shell elements with eight nodes and six degrees of freedom at each node: translations in the $x, y$, and $z$ axes and rotations about the $x, y$, and $z$ axes. Figure 5 shows the global FE model of Hall $B$ and the various materials used represented with different colours.

In order to simulate different damage scenarios, two FEMs were built: FEM1 considers the structure in its integrity, with infill walls (Figure 6(a)) and FEM2, instead, represents the structure without infill walls, in order to simulate a full damage state for nonstructural elements during the ground motion (Figure 6(b)). FEM1 has 60,782 elements and 221,004 nodes. FEM2, instead, counts 55,887 elements and 192,038 nodes. After a static validation of the models, the FE eigenvalue problems were solved in order to evaluate the main modal characteristics in both damaged and undamaged states.

The structure was assumed to be clamped at the base. Furthermore, in this linear FEM, the continuum underlying the structure was disregarded. Material properties were deduced partly from the values founded in literature in Nervi's projects and partly from typical values of the period $[30,39]$. As a result, the material properties are assumed as shown in Table 1. Table 1 is reproduced from [43] (under the Creative Commons Attribution License/public domain).

In order to evaluate the dynamic response of the spatial structure built by Pier Luigi Nervi, as well as to identify the higher vulnerabilities factor of the complex, a series of elastic analyses of the entire undamaged building were performed. Different analyses were undertaken in order to estimate the influence of different structural elements on the global behaviour of the hall.

Modes are classified based on a criterion of the mass percentage participation along the $x, y$, and $z$ directions and torsion around the $z$ axis. The selection was based partly on the mass participation percentage factor. 


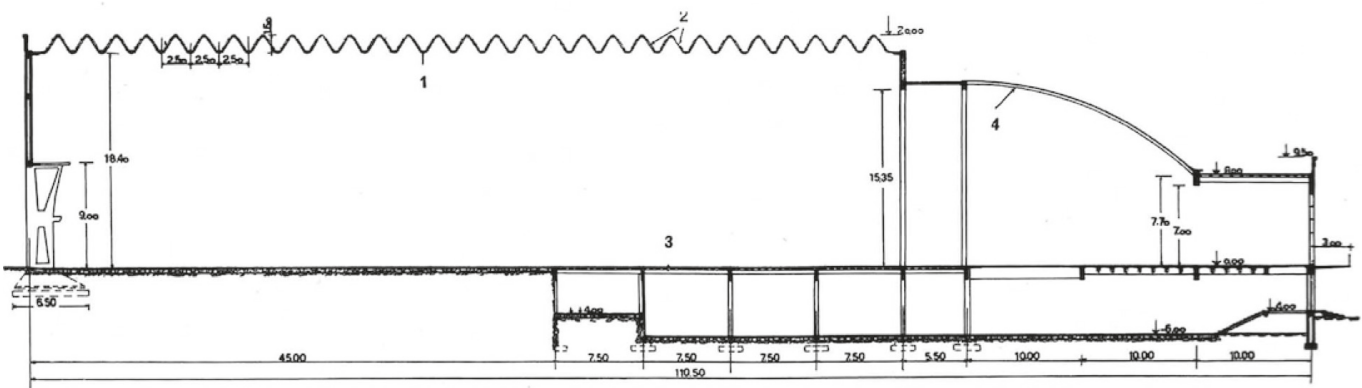

(a)

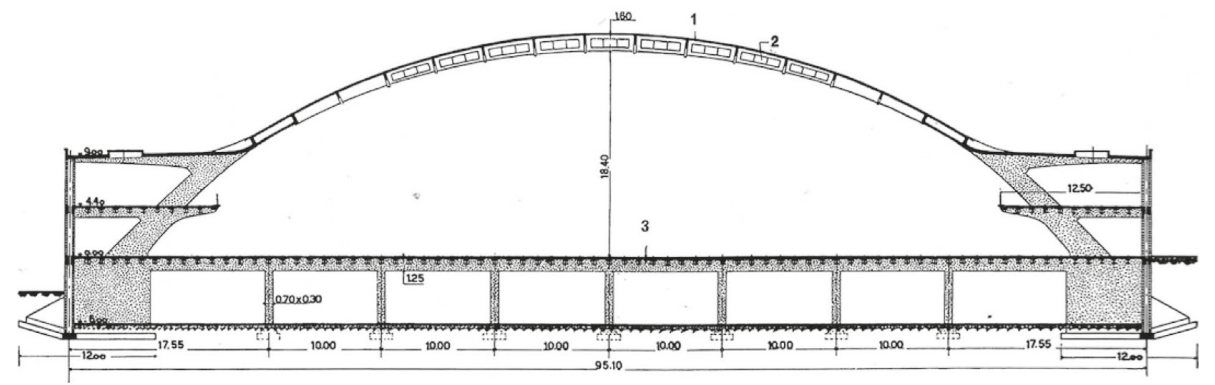

(b)

Figure 3: Sections of Hall B [34].

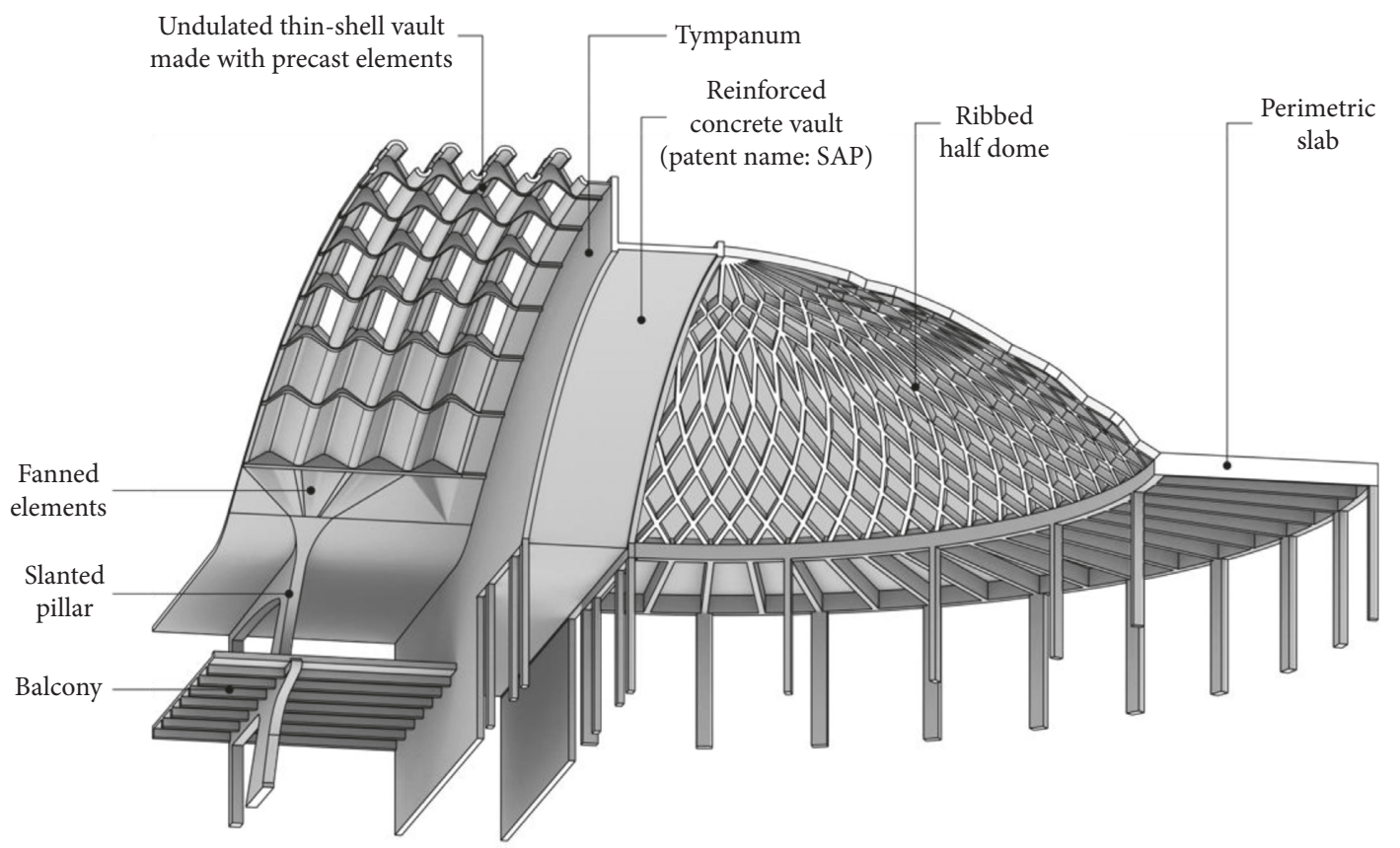

Figure 4: The main structural elements of Hall B. Detail of the joint between the ribbed half-dome and the undulated vault of the hall.

3.3.1. Linear-Elastic FEM Analysis of the Undamaged Building (FEM1). As a first step, a series of elastic analyses of the entire undamaged building were performed, with the aim of obtaining a preliminary rough description of the overall structural behaviour. The eigenvalue problem was solved considering dead loads. The first 100 modes were extracted from the model. Some of the principal modes are listed from Figures 7-10. Table 2 illustrates the principal modal properties of the structure, selected by mass percentage participation and considering the possible activation of local mechanisms as well.

3.3.2. Damaged Configuration (FEM2). In order to simulate different damage scenarios, the second model of Hall B (FEM2) was built without infill walls, so as to simulate a full 


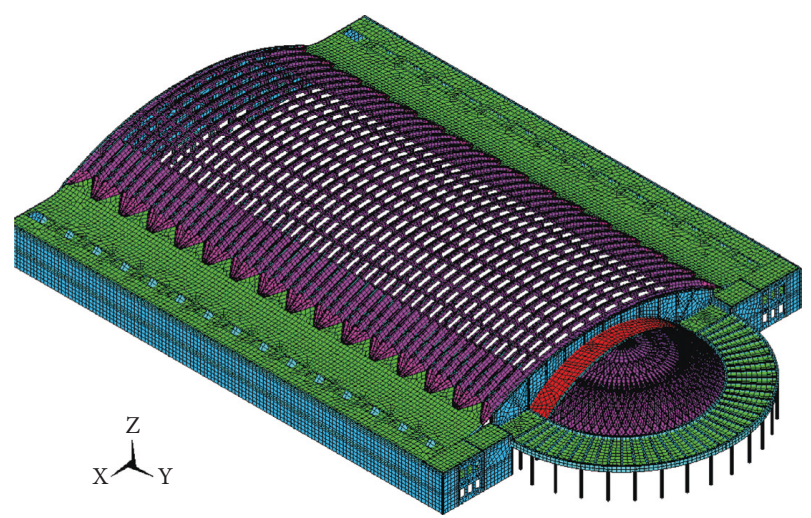

Figure 5: A 3D view of the global finite element model of the hall showing its mesh and different materials (classified by colours).

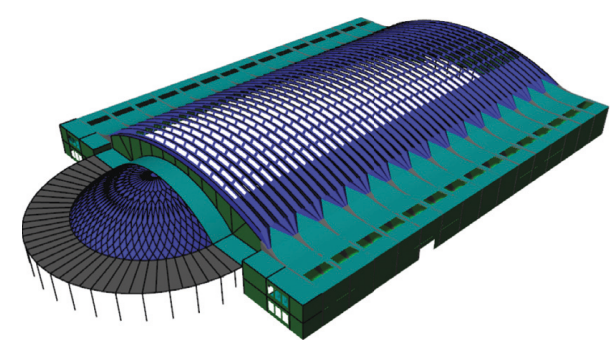

(a)

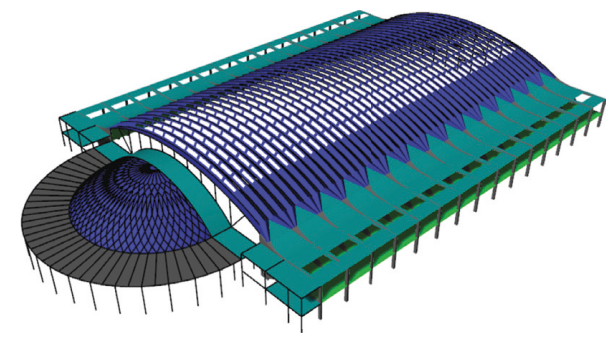

(b)

Figure 6: Geometrical model of Hall B with infill walls (a) and in its damaged configuration (b).

damage state for nonstructural elements during the ground motion. In this case again, the modal shapes were calculated considering dead loads. The first 100 modes were extracted from the model, and some the main modes are listed from Figures 11-15. Table 3 shows the modal properties of the structure and the principal modes and their classification.

\subsubsection{Discussion of FEM Results: Emerging Issues and Critical} Elements. As it emerges from the previous sections, the building presents a complex configuration. In fact, even if it presents a symmetrical form, both halls exhibit a large variety of structural elements. Moreover, especially in the case of Hall B, the large hall structure is at the same time very thin and overall lightweight.

From a comparison of the results of the different FE models, the main issues to be raised concern the out-of-theplane movements of the tympanums, as highlighted by low-
TABLE 1: Materials and properties.

\begin{tabular}{lccc}
\hline Material & $E(\mathrm{GPa})$ & Poisson's ratio & $\rho\left(\mathrm{kg} / \mathrm{m}^{3}\right)$ \\
\hline Ferrocement & 26 & 0.2 & 2,500 \\
Masonry (infill walls) & 2 & 0.2 & 1,100 \\
Reinforced concrete & 30 & 0.2 & 2,500 \\
Reinforced concrete slabs & 21 & 0.2 & 1,250 \\
\hline
\end{tabular}

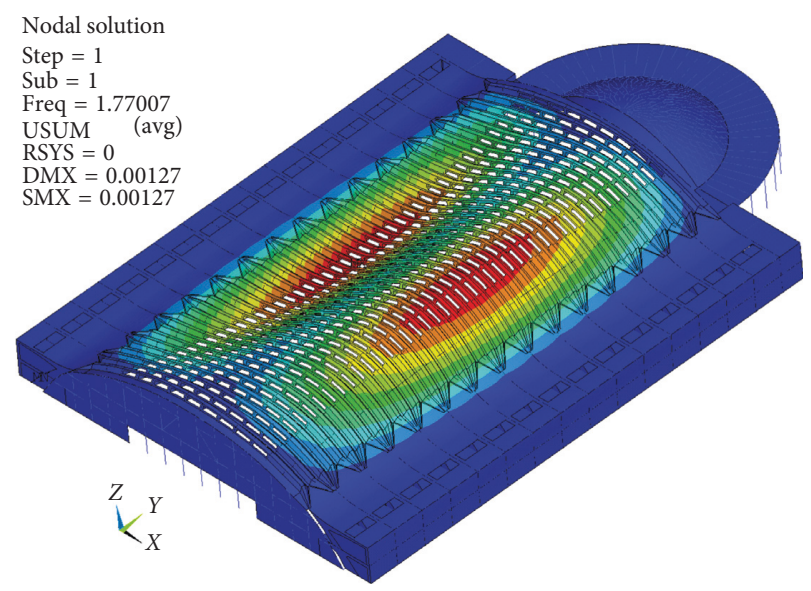

Figure 7: Mode 1 of Hall B (front view).

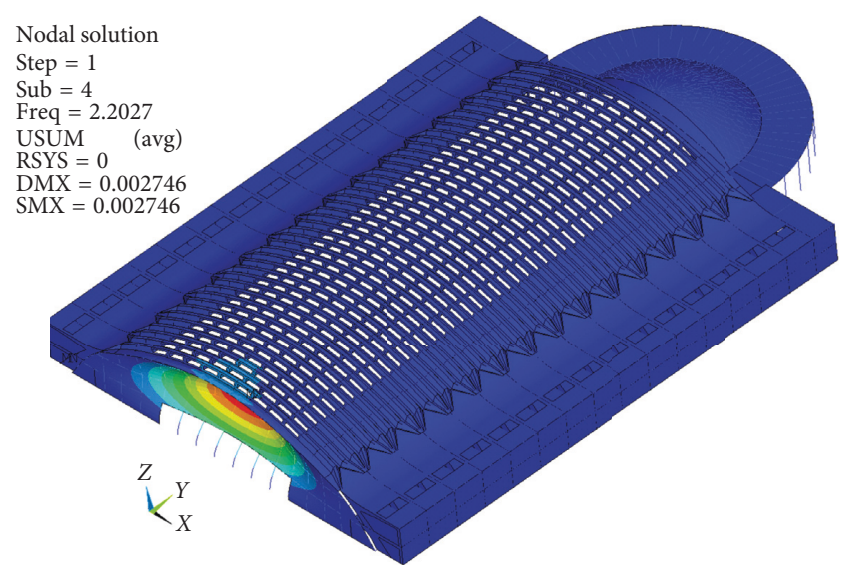

Figure 8: Mode 4 of Hall B (front view).

frequency vibration modes (Figure 8). The movements of the large undulated vault could induce this type of behaviour, especially in relation with the body of the apse (Figure 9). Another issue to be evidenced regards the flexural modes of the undulated thin-shell vault (Figures 7 and 12). Due to Nervi's structural conception, in Hall B, this mode happens to fall in an amplified region of the typical seismic response spectrum. This type of behaviour is ascribed to the inertial mass of the out-of-plane elements, including nonstructural ones. It can also be observed that when not effectively contrasted, these out-of-plane movements constitute a serious vulnerability factor for the entire hall, as they may induce overturning, pounding, and interaction with structural and nonstructural elements (e.g., the interaction 


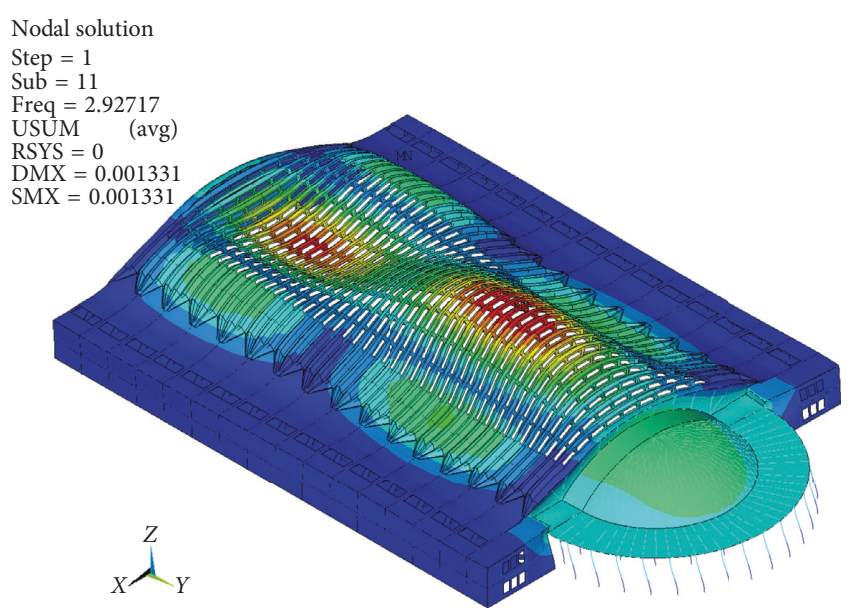

Figure 9: Mode 11 of Hall B (apse view).

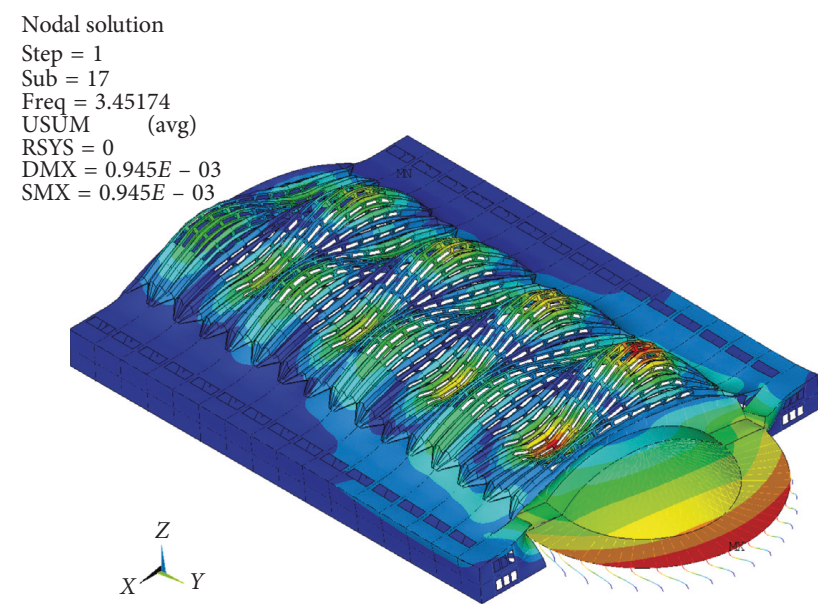

Figure 10: Mode 17 of Hall B (apse view).

between the tympanum and the half-dome) (Figures 9 and 14). Finally, it should be noted that the presence of the apse constitutes a further element of criticality, due to its complex interaction with the main body of the hall (Figures 9 and 10). This type of behaviour is somehow similar to the one often observed in other buildings characterized by large halls, including churches. Indeed, models for such peculiar structures cannot overlook the effect of nonstructural elements, also in view of their possible mechanical degradation during a strong motion.

The analyses evidence an inherent criticality of this kind of structure to seismic actions. This is expected to happen especially in the presence of heavy structural elements, which are conceived to withstand important gravity loads. In addition, the model must take into account the effect of nonstructural elements, as well as their possible mechanical degradation during a strong motion. In particular, infill walls exhibit a typically elastic-brittle behaviour. Such premises constitute critical aspects that will affect the design of a vibration-based monitoring system.

\section{An OSP-Based Monitoring System for HALL $B$ of the Turin Exhibition Centre}

In order to design an optimal monitoring system for Hall B of Turin Exhibition Centre, that currently is not monitored, the FE models were firstly used to identify the main structural portions and elements that affect the dynamic behaviour of the structure. Based on the FE vibration modes, the sets of measuring points (henceforth termed setups) were defined.

As anticipated in Section 2.2, a simple and robust criterion for the solution of the problem of optimal placement of accelerometers was chosen. It refers to the mentioned Genetic Algorithm that uses as objective function the simple subtraction of terms related to the MAC [20], a matrix containing element indices of the correspondence of two modal vectors.

The OSP algorithm was applied to Hall B of Turin Exposition Centre. The FE models enabled to locate the main structural elements that affect the dynamic behaviour of the structure and calculate the solution of the eigenvalue problem. The measuring points were defined based on the FE vibration modes.

The setup chosen for Hall B has 245 possible positions for accelerometers corresponding to 651 channels. Positions were distributed on the macroelements of the building previously identified: the tympanums, the undulated vault, the SAP vault, the ribbed half-dome, the concrete fans, and the slanted pillars. The candidate channel positions are reported in Figure 16. Accordingly, the candidate channels were distributed as follows: 245 channels in the $x$ direction, 245 channels in the $y$ direction, and 161 channels in the $z$ direction. Channels in the $z$ direction have a lower number according to the fact that in this direction, only the movements of vault and the half-dome are considered significant.

In addition to their ideal positioning, different scenarios were explored by varying the number of sensors from 2 to 100. This variation range for the number of sensors was selected based both on total cost and computational reasons.

The possible variations in the optimal sensor placement were also investigated, considering the presence or the absence of the nonstructural elements such as the infill walls. For this reason, the OSP algorithms were applied first on the structure with infill walls, then on the structure without. The algorithm required some numerical constraints, such as a limited number of sensors and a limited number of potential positions. With these premises, different setups were considered.

As seen in the previous sections, nonstructural elements may importantly affect the vibration modes, and consequently the OSP. For this reason, it was decided to develop a damage-scenario-driven sensor placement strategy, and the optimisation algorithm was run on the structure accounting for damage scenarios. A first setup was designed based on the undamaged configuration, that is, the setup accounting for the infill walls. The second setup, instead, was associated to the damaged structure (bare structure), in the 
TABLE 2: Modal properties of Hall B and classification of the main vibration modes, considering the presence of the infill walls.

\begin{tabular}{|c|c|c|c|c|c|}
\hline \multirow{2}{*}{ Mode } & \multirow{2}{*}{$\begin{array}{c}\text { Frequency } \\
\mathrm{Hz}\end{array}$} & \multicolumn{3}{|c|}{ Mass fraction } & \multirow{2}{*}{ Mode classification } \\
\hline & & $x$ & $y$ & $z$ & \\
\hline 1 & 1.770 & 0.119 & 0.000 & 0.000 & 1st bending $X$ : vault \\
\hline 2 & 1.937 & 0.001 & 0.000 & 0.000 & 2nd bending $X$ : vault \\
\hline 4 & 2.203 & 0.000 & 0.082 & 0.000 & 1st bending $Y$ : front tympanum \\
\hline 7 & 2.660 & 0.000 & 0.017 & 0.002 & 2nd bending $Y$ : vault and aspe \\
\hline 9 & 2.863 & 0.000 & 0.156 & 0.000 & 3rd bending $Y$ : pounding between the apse and the vault \\
\hline 11 & 2.927 & 0.000 & 0.195 & 0.000 & 4th bending $Y$ : vault and apse \\
\hline 17 & 3.452 & 0.230 & 0.000 & 0.000 & Aspe mechanism \\
\hline 26 & 3.981 & 0.246 & 0.000 & 0.000 & Vault and fanned elements \\
\hline 32 & 4.507 & 0.000 & 0.001 & 0.003 & Vault and fanned elements \\
\hline 39 & 4.945 & 0.000 & 0.040 & 0.011 & Apse and tympanum \\
\hline 47 & 5.379 & 0.000 & 0.058 & 0.010 & Apse and tympanum \\
\hline 50 & 5.505 & 0.125 & 0.000 & 0.000 & Vault \\
\hline 53 & 5.694 & 0.000 & 0.000 & 0.000 & Tympanums mechanism \\
\hline 66 & 6.306 & 0.000 & 0.005 & 0.561 & Vault \\
\hline 97 & 7.297 & 0.007 & 0.000 & 0.000 & Vault and apse \\
\hline
\end{tabular}

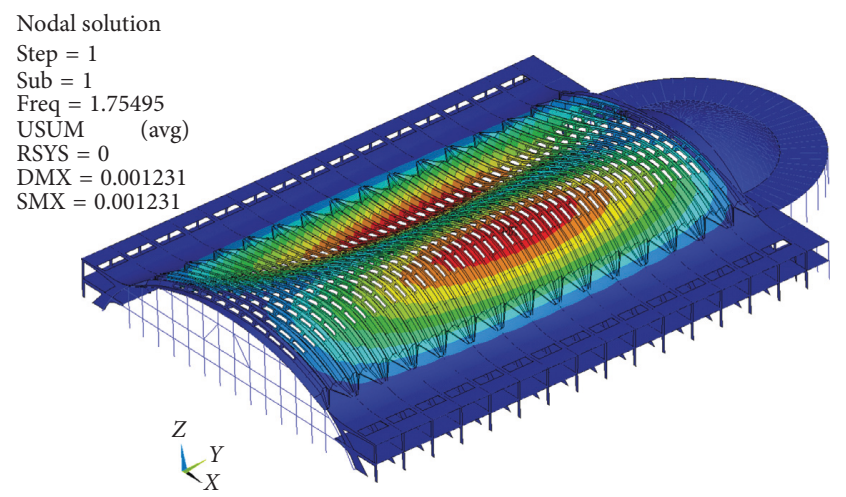

Figure 11: Mode 1 of Hall B in its damaged configuration (front view).

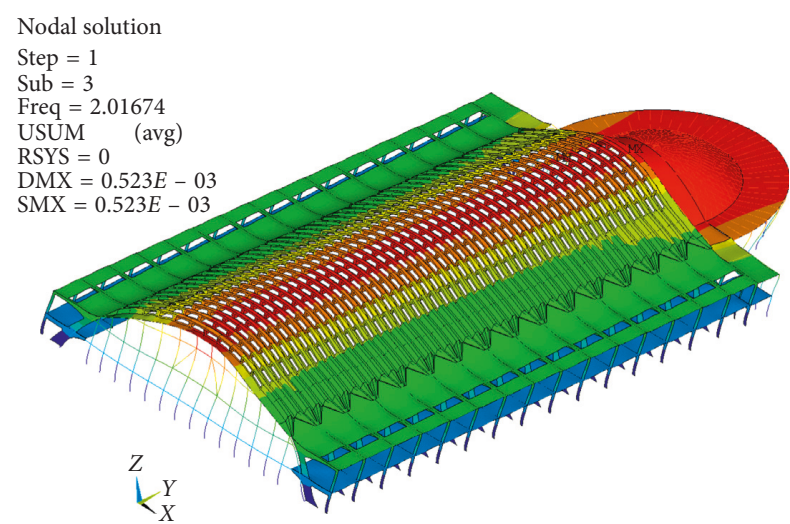

Figure 12: Mode 3 of Hall B in its damaged configuration (front view).

assumption that all nonstructural elements would undergo a complete degradation at the end of the strong motion. The algorithms were developed using the MATLAB software.

The charts in Figure 17 depict the final error in the objective function corresponding to the two optimised

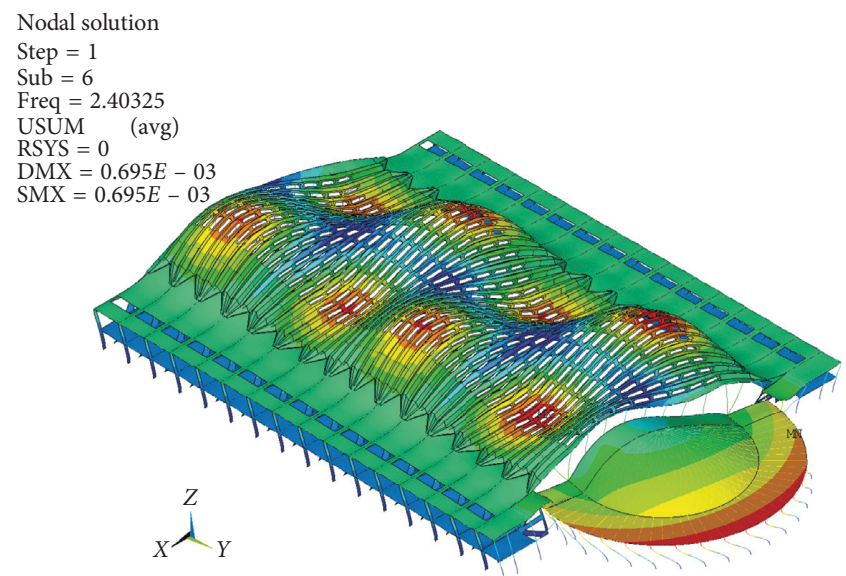

FIgURE 13: Mode 6 of Hall B in its damaged configuration (apse view).

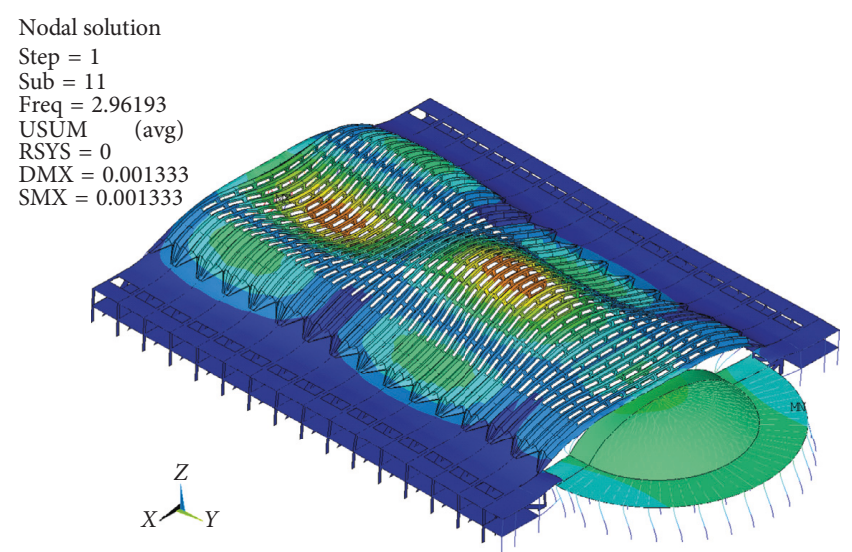

FIGURE 14: Mode 11 of Hall B in its damaged configuration (apse view).

configurations for Hall B. The abscissa represents the number of sensors used by different sensor placements. While error for the damaged structure stabilizes at around 


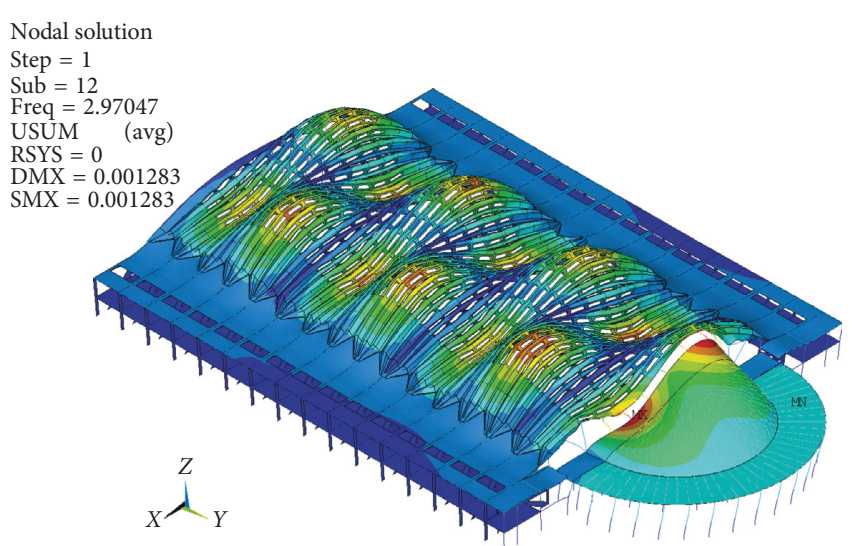

FIGURE 15: Mode 12 of Hall B in its damaged configuration (apse view).

TABLE 3: Modal properties of the structure and classification of the main vibration modes, considering the damage of the infill walls.

\begin{tabular}{|c|c|c|c|c|c|}
\hline \multirow{2}{*}{ Mode } & \multirow{2}{*}{$\begin{array}{c}\text { Frequency } \\
\mathrm{Hz}\end{array}$} & \multicolumn{3}{|c|}{ Mass fraction } & \multirow{2}{*}{ Mode classification } \\
\hline & & $x$ & $y$ & $z$ & \\
\hline 1 & 1.7550 & 0.143 & 0.000 & 0.000 & 1st bending $X$ : vault \\
\hline 3 & 2.0167 & 0.000 & 0.882 & 0.000 & $\begin{array}{l}\text { 1st bending } Y \text { : vault } \\
\text { and apse }\end{array}$ \\
\hline 6 & 2.4033 & 0.058 & 0.000 & 0.000 & $\begin{array}{c}\text { 2nd bending } X \text { : vault } \\
\text { and apse }\end{array}$ \\
\hline 11 & 2.9619 & 0.000 & 0.018 & 0.001 & $\begin{array}{l}\text { 2nd bending } Y \text { : } \\
\text { pounding between the } \\
\text { apse and the vault }\end{array}$ \\
\hline 12 & 2.9705 & 0.084 & 0.000 & 0.000 & Apse and SAP slab \\
\hline 16 & 3.2535 & 0.000 & 0.006 & 0.000 & Tympanum \\
\hline
\end{tabular}

20 sensors, the undamaged configuration appears to call for additional sensors. This result is to be ascribed to the influence of local movements activated at the infill walls (nonstructural elements). In Figure 17, it is also possible to note how the error increases after reaching a certain number of sensors. This is due to the fact that a large number of sensors increase the difficulties in the decoupling of the modal parameters.

The optimal solutions found by the algorithm, in the investigated range of modes, are illustrated in Figure 18, for the two cases (with and without infill walls). From the optimal sensor configurations (Figures 18(a) and 18(b)), the distribution of the sensors in the two layouts is clearly different. In setup (a), the sensors are mainly located on the undulated vault and, contrary to setup (b), the vertical movements appear to be more important. In general, setup (a) is characterized by monitoring of vertical vibrations. By contrast, in setup (b), where the nonstructural elements are not taken into account, many sensors are distributed in order to monitor translational movements. Most of the sensors are positioned along the minor defence line in the $Y$ direction. This is due to the missing stiffening contribution of the infill wall, which is particularly important in this direction (Figure 12).

From the location of sensors, it appears that the local mechanisms previously described strongly influence the placement of sensor. For this reason, a weighting coefficient was applied to the modal shapes of the structure. Subsequently, the optimisation was performed by weighting different contributions on the basis of the importance of the different modes. The introduction of the weighting coefficients led to an improvement of the decoupling performance. As it can be seen in Figure 19, in the configuration setup for the undamaged structure, the sensors are more distributed on the apse system and especially on the transition between the undulated vault and the apse: the tympanum and the SAP vault.

4.1. Damage-Driven Approach to OSP. As it emerged from the results previously reported, the influence of nonstructural elements and their interaction with the structure cannot be neglected when designing a dynamic monitoring system. In particular, it was observed that when nonstructural elements, such as infill walls, undergo seismic damage or degradation, they may significantly affect the global dynamic response. Such an aspect is even more important for historical spatial structures, built in a period when seismic or other dynamic actions were not taken into account in the design process. These structures were frequently conceived on the basis of gravity loads, and this purpose is clearly expressed in their design. A development of these observations could consist in a modification of the form of the objective function that takes into account different seismic damage scenarios [43]. The optimal sensor placement applied for this case study is obtained through a modified objective function. Equation (2) is accordingly updated:

$$
\text { error }_{\text {mod }}=\operatorname{error}_{w}+\text { error }_{b} \text {, }
$$

where error $_{w}$ and error ${ }_{b}$ have the same expression as reported in (2), but are referred to the structure with the infill walls and to the bare structure without the infill walls, respectively.

Figure 21 reports the optimal sensor configurations obtained for the mixed configuration for Hall B. The integrated design strategy of the monitoring system permits a more rational use of the instruments, in which most sensors appear to be less dispersed and localized in those elements that govern the seismic response of the building: the vault (B), the front tympanum, and the apses (D), (E), and (F) (Figure 16).

\section{Conclusions}

This study concerned OSP methods to be used in the design of seismic monitoring systems for concrete spatial structures, with special emphasis on the vaulted structures built by Pier Luigi Nervi. Sensor placement strategies for such peculiar structures should include in their formulations the possible damage and stiffness degradation in infill walls and other nonstructural elements. Accordingly, the objective function used to optimise the sensor positions must conform to a damage-scenario-driven strategy. In this paper, a scenario-driven OSP was applied to one of the most magnificent and complex structures ever conceived by Nervi, that is, Hall B of Turin Exhibition Centre. 


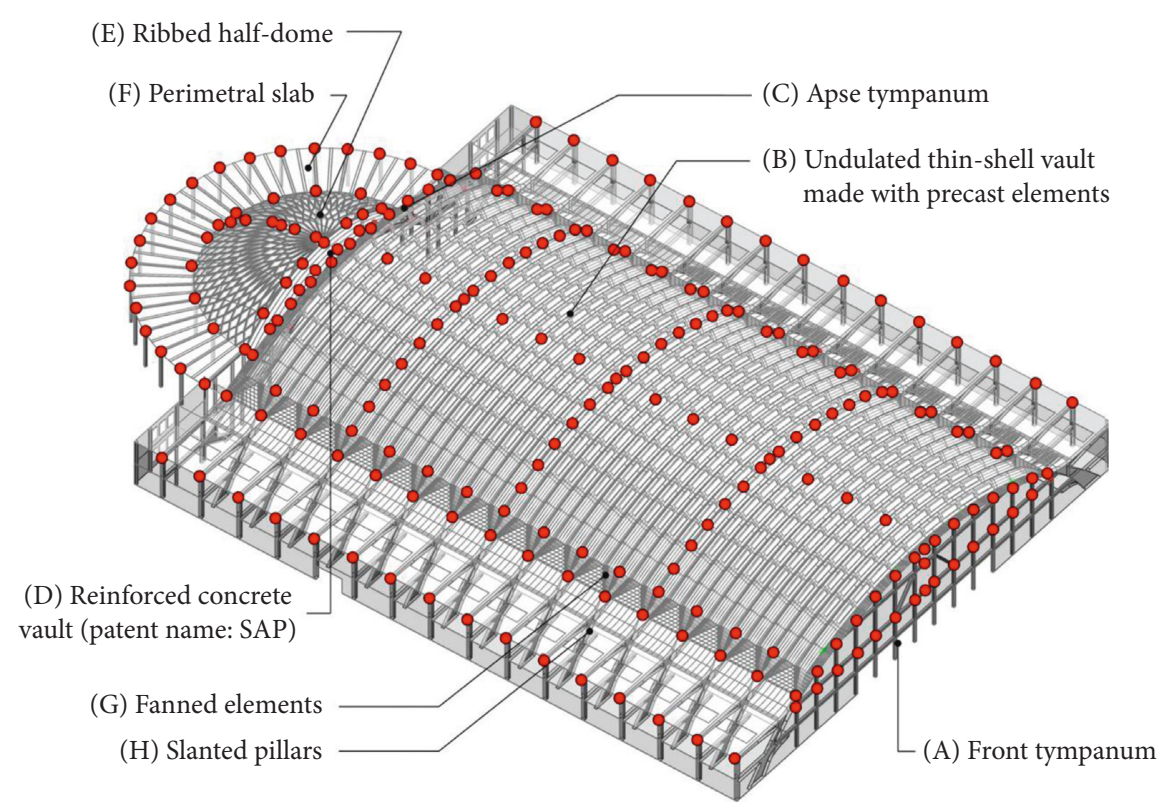

Figure 16: A 3D view of Hall B showing its macroelements and the possible sensor positions.

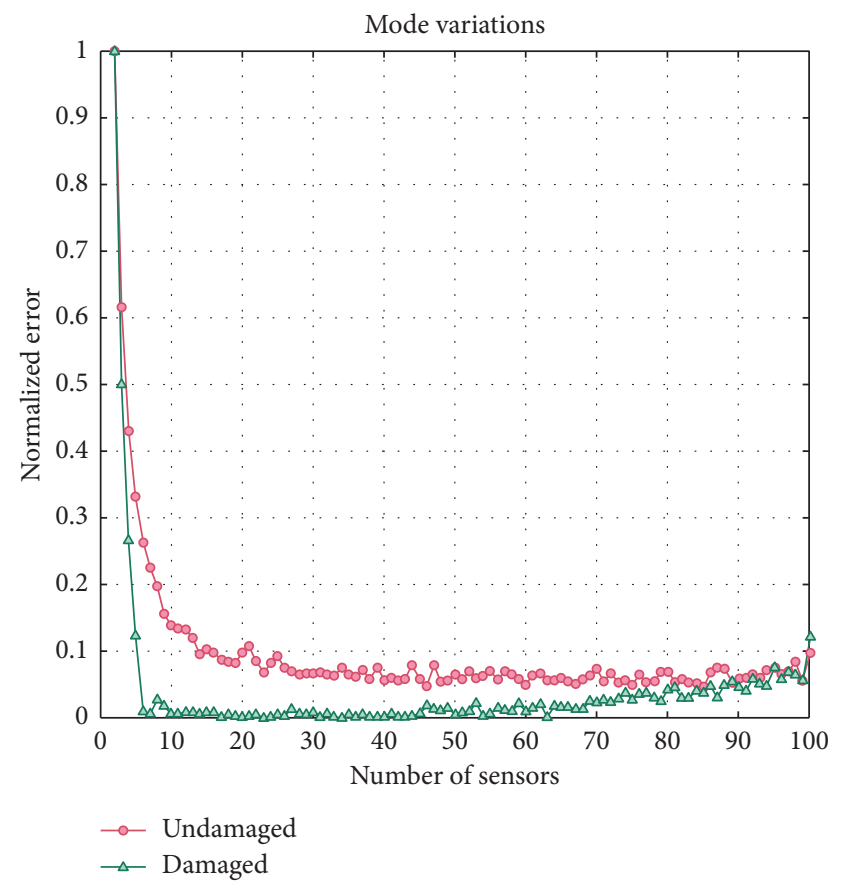

FIGURE 17: Normalized error function of the structure accounting for different scenarios: undamaged and damaged structure of Hall B.

This type of research necessarily entails an increase in the level of knowledge on the constituting elements and construction details, as well as to gain a better understanding of the design concept of the structural system of Hall B, designed and constructed by Nervi between 1948 and 1949. A numerical study was carried out accordingly. The analysis performed for this building suggests that in most cases, large concrete buildings conceived in the postwar period are

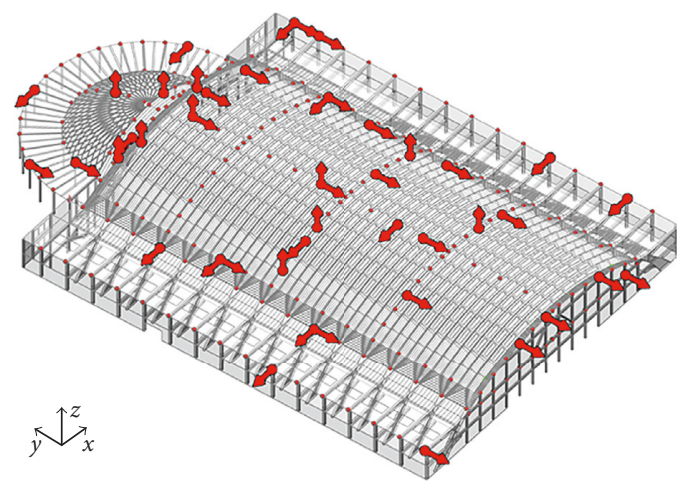

(a)

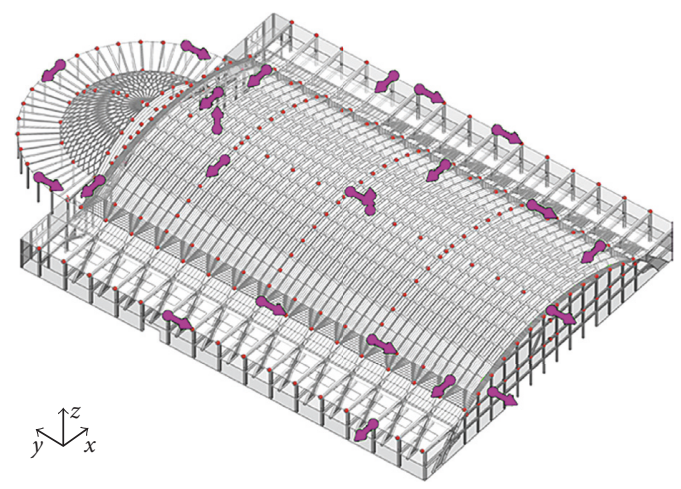

(b)

FIGURE 18: Sensor configuration layout: setup (a) shows the OSP for the undamaged structure and setup (b) represents the OSP for the damaged structure.

inherently vulnerable with respect to seismic actions. This is especially true in the presence of heavy structural elements conceived to withstand high gravity loads, like in Hall C of the same Turin Exhibition Centre. As a result, after the 


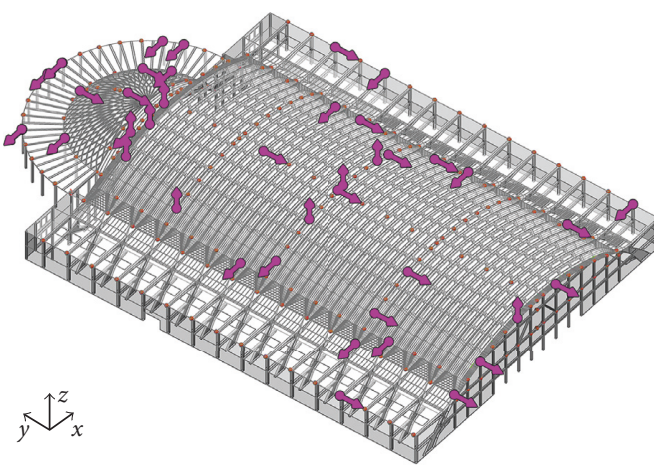

(a)

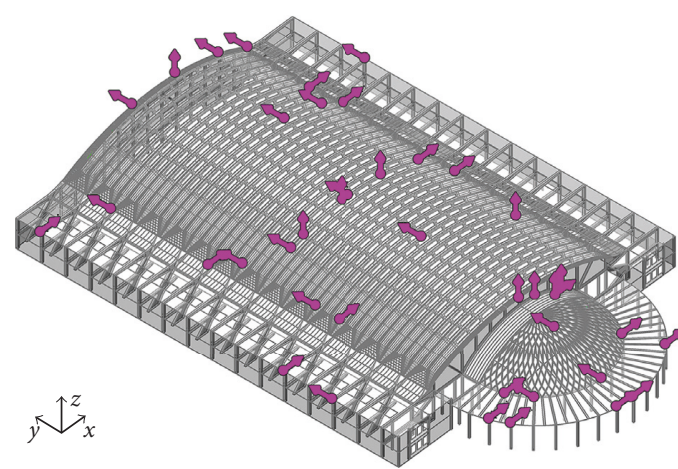

(b)

FIGURE 19: Sensor configuration layout: placement of sensors for the undamaged structure, after the weighting of the different contributions. Also in the damaged configuration, there was an improvement in the placement of sensors. The sensors are oriented especially in the $y$ direction Figure 20.

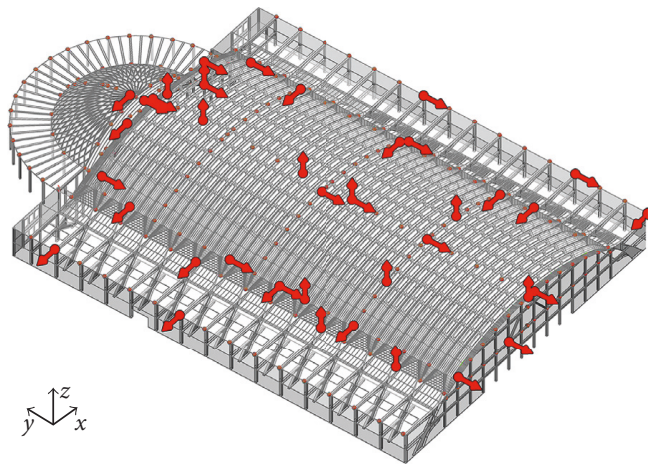

(a)

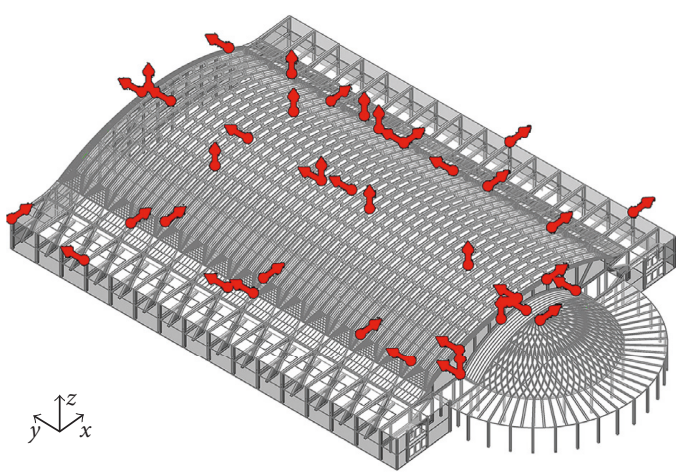

(b)

FIGURE 20: Sensor configuration layout: placement of sensors for the damaged structure, after the weighting of the different contributions.

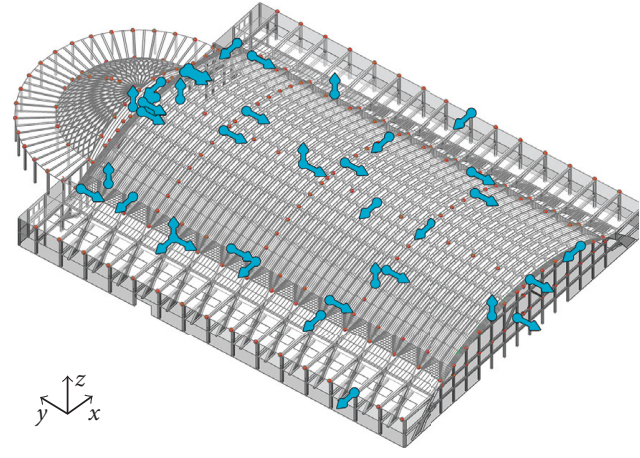

(a)

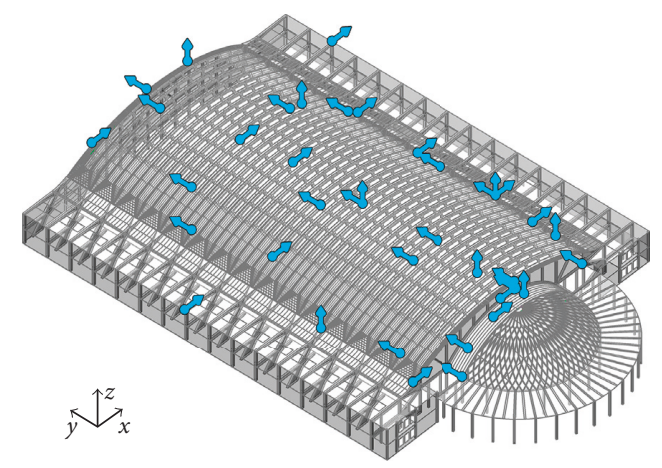

(b)

FIgURE 21: The mixed configuration setup applied to Hall B.

recent reclassification of the Italian territory, the seismic actions cannot be neglected. The Turin Exhibition Complex is located in a low seismic area but, in view of its reuse, it cannot be considered as safe with respect to seismic actions. In fact, the vibration modes of Hall B highlight several critical elements to seismic actions.
In Hall B, critical mechanisms appear to affect the tympanums in the out-of-plane direction, which are induced by the movements of the large undulated vault. In addition, when not effectively contrasted, these out-of-plane movements may induce overturning, pounding, and interaction with structural and nonstructural elements (e.g., the 
interaction between the tympanum and the half-dome). Finally, it has been shown that additional irregularities in the response are potentially introduced by the presence of the apse due to its complex interaction with the main body of the hall. This type of behaviour is somehow similar to the one often observed in other structures characterized by large halls, including churches.

To conclude, numerical investigations confirmed that nonstructural elements strongly affect the dynamic behaviour of the structure and, consequently, the sensor placement of vibration-based monitoring systems. In this respect, this study demonstrated that the damage-scenario-driven OPS strategy is an efficient design tool.

\section{Data Availability}

The data used to support the findings of this study are available from the corresponding author upon request.

\section{Conflicts of Interest}

The authors declare that they have no conflicts of interest.

\section{References}

[1] M.-G. Masciotta, L. F. Ramos, and P. B. Lourenço, "The importance of structural monitoring as a diagnosis and control tool in the restoration process of heritage structures: a case study in Portugal," Journal of Cultural Heritage, vol. 27, pp. 36-47, 2017.

[2] F. Ubertini, G. Comanducci, and N. Cavalagli, "Vibrationbased structural health monitoring of a historic bell-tower using output-only measurements and multivariate statistical analysis," Structural Health Monitoring, vol. 15, no. 4, pp. 438-457, 2016.

[3] R. Ceravolo, G. Pistone, L. Zanotti Fragonara, S. Massetto, and G. Abbiati, "Vibration-based monitoring and diagnosis of cultural heritage: a methodological discussion in three examples," International Journal Architectural Heritage, vol. 10, no. 4, pp. 375-395, 2017.

[4] D. C. Kammer and M. L. Tinker, "Optimal placement of triaxial accelerometers for modal vibration tests," Mechanical Systems and Signal Processing, vol. 18, no. 1, pp. 29-41, 2004.

[5] U. Muthuraman, M. M. Sai Hashita, N. Sakthieswaran, P. Suresh, M. Raj Kumar, and P. Sivashanmugam, "An approach for damage identification and optimal sensor placement in structural health monitoring by genetic algorithm technique," Circuits and Systems, vol. 7, no. 6, pp. 814-823, 2016.

[6] Q. Boying and L. Xiankun, "Optimal sensor placement based on particle swarm optimization," Advanced Materials Research, vol. 271-273, pp. 1108-1113, 2011.

[7] T. Yi, H. Li, and M. Gu, "Optimal sensor placement for structural health monitoring based on multiple optimization strategies," Structural Design of Tall and Special Buildings, vol. 20, pp. 881-900, 2011.

[8] D. Kammer, "Sensor placement for on-orbit modal identification and correlation of large structures," Journal of Guidance, Control and Dynamics, vol. 14, no. 2, pp. 251-259, 1991.

[9] M. Salama, T. Rose, and J. Garba, "Optimal placement of excitations and sensors for verification of large dynamical systems," in Proceedings of the 28th Structures, Structural
Dynamics and Materials Conference, Monterey, CA, USA, April 1987.

[10] Y. Chung and J. Moore, "On-orbit sensor placement and system identification of space station with limited instrumentation," in Proceedings of the 11th International Modal Analysis Conference, Kissimmee, FL, USA, February 1993.

[11] R. D. Henshell and J. H. Ong, "Automatic masters for eigenvalue economization," Earthquake Engineering and Structural Dynamics, vol. 3, no. 4, pp. 375-383, 1974.

[12] K. Worden and A. P. Burrows, "Optimal sensor placement for fault detection," Engineering Structures, vol. 23, no. 8, pp. 885-901, 2001.

[13] D. Li, H. Li, and C. Fritzen, "The connection between effective independence and modal kinetic energy methods for sensor placement," Journal of Sound and Vibration, vol. 305, no. 4-5, pp. 945-955, 2007.

[14] C. Chisari, L. Macorini, C. Amadio, and B. Izzuddin, "Optimal sensor placement for structural parameter identification," Structural and Multidisciplinary Optimization, vol. 55, no. 2, pp. 647-662, 2017.

[15] D. S. Li, H. N. Li, and C. P. Fritzen, "Representative least squares methods for sensor placement," in Proceedings of the 3rd International Conference on Structural Health Monitoring and Intelligent Infrastructure, Vancouver, BC, Canada, November 2007.

[16] L. F. Ramos, R. Aguilar, P. B. Lourenco, and S. Moreira, "Dynamic structural health monitoring of Saint Torcato church," Mechanical Systems and Signal Processing, vol. 35, no. 1-2, pp. 1-15, 2013.

[17] D. Goldberg, Genetic Algorithms in Search, Machine Learning and Optimisation, Addison Wesley, New York, NY, USA, 1989.

[18] L. Yao, W. A. Sethares, and D. C. Kammer, "Sensor placement for on-orbit modal identification via a genetic algorithm," AIAA Journal, vol. 31, no. 10, pp. 1922-1928, 1993.

[19] T. Marwala, Finite-Element-Model Updating Using Computational Intelligence Techniques: Applications to Structural Dynamics, Springer, Berlin, Germany, 2010.

[20] R. Allemang and D. Brown, "A correlation coefficient for modal vector analysis," in Proceedings of the 1st International Modal Analysis Conference, Orlando, FL, USA, November 1982.

[21] R. Allemang, "The modal assurance criterion-twenty years of use and abuse," Sound and Vibration, vol. 37, no. 8, pp. 14-21, 2003.

[22] K. C. Normandin and S. Macdonald, "A colloquium to advance the practice of conserving modern heritage," Meeting Report, The Getty Conservation Institute, Los Angeles, CA, USA, 2013.

[23] T. Prudon, Preservation of Modern Architecture, John Wiley \& Sons, Inc., Hoboken, NJ, USA, 2008.

[24] J. Abel, G. Arun, and M. Chiorino, "Special double issue on Pier Luigi Nervi: preface by the guest editors," Journal of the IASS, vol. 54, no. 176-177, pp. 79-86, 2013.

[25] C. Chiorino and C. Olmo, Pier Luigi Nervi: Architecture as Challenge, Silvana Editoriale, Milano, Italy, 2010.

[26] N. Pevsner, "A Master Builder," The New York Review of Books, vol. 6, no. 3, 1966.

[27] S. Gideion, Space, Time and Architecture: The Growth of a New Tradition, Harvard University Press, Cambridge, MA, USA, 3rd edition, 1941.

[28] D. Billington, Tower and the Bridge: The New Art of Structural Engineering, Princeton University Press, Princeton, NY, USA, 1985. 
[29] F. Albani and C. Dusi, "Thin concrete shell: repair and maintenance strategies," in Proceedings of the 4th Workshop on The New Boundaries of Structural Concrete, Anacapri, Italy, September-October 2016.

[30] C. Greco, "The "ferro-cemento" of Pier Luigi Nervi, the new material and the first experimental Building," in Proceedings of the International Symposium of IASS, Padova, Italy, 1995.

[31] T. Leslie, "Moving weights: Nervi's prefabricated 'Wave Ashlar' roofs and the artisanal cantiere," in Proceedings of the IASS-SLTE 2014 Symposium "Shells, Membranes and Spatial Structures: Footprints, Brasilia, Brazil, September 2014.

[32] E. Lenticchia, R. Ceravolo, and C. Chiorino, "Optimal sensor placement for modern heritage spatial structures," in Proceedings of the 10th International Conference on Structural Analysis of Historical Constructions (SAHC), Leuven, Belgium, September 2016.

[33] P. Nervi, Aesthetics and Technology in Building: The Charles Eliot Norton Lectures, Harvard University Press, Cambridge, MA, USA, 1965.

[34] P. Nervi, "La struttura portante del nuovo Salone del Palazzo di Torino Esposizioni," Rassegna Tecnica Della Società Degli Ingegneri e Architetti in Torino, vol. 4, no. 1-3, 1950.

[35] C. Greco, Pier Luigi Nervi: Dai Primi Brevetti al Palazzo Delle Esposizioni di Torino 1917-1948, Lucerne Quart Edizioni, Lucerne, Switzerland, 2008.

[36] T. Iori and S. Poretti, "Pier Luigi Nervi: his construction system for shell and spatial structures," Journal of the IASS, vol. 54, no. 176-177, pp. 117-126, 2013.

[37] P. L. Nervi, "Le strutture portanti del Palazzo per le Esposizioni al Valentino," Rassegna Tecnica Della Società Degli Ingegneri e Architetti in Torino, vol. 2, no. 7, 1948.

[38] T. Leslie, "Carpenter's parametrics: economics, efficiency, and form in Pier Luigi Nervi's concrete designs," Journal of the IASS, vol. 54, no. 176-177, pp. 107-115, 2013.

[39] P. L. Nervi, Palazzo Delle Esposizioni-Torino, Centro Studi e Archivio della Comunicazione (CSAC), Parma, Italy, 1948.

[40] F. Romeo, "Presenting Nervi's work through scale models: the NerViLaB," Journal of the International Association for Shell and Spatial Structures, vol. 54, no. 176-177, pp. 211-220, 2013.

[41] F. Antonucci, R. Ceravolo, E. Lenticchia, and B. Ranaldo, "Sensor placement strategies with application to the Hall B of Torino Esposizioni by Pier Luigi Nervi," in Proceedings of the IASS Annual Symposium on Interfaces: Architecture.Engineering.Science, Hamburg, Germany, September 2017.

[42] RDB, Erredibi Piacenza, Manualetto. Murature, Solai, Coperture: Dati Tecnici Estratti dal Bollettino 'Il Laterizio', RDB, Piacenza, Italy, 1958.

[43] E. Lenticchia, R. Ceravolo, and C. Chiorino, "Damage scenario-driven strategies for the seismic monitoring of $\mathrm{XX}$ century spatial structures with application to Pier Luigi Nervi's Turin Exhibition Centre," Engineering Structures, vol. 137, pp. 256-267, 2017. 


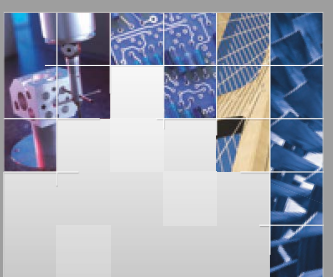

\section{Enfincering}
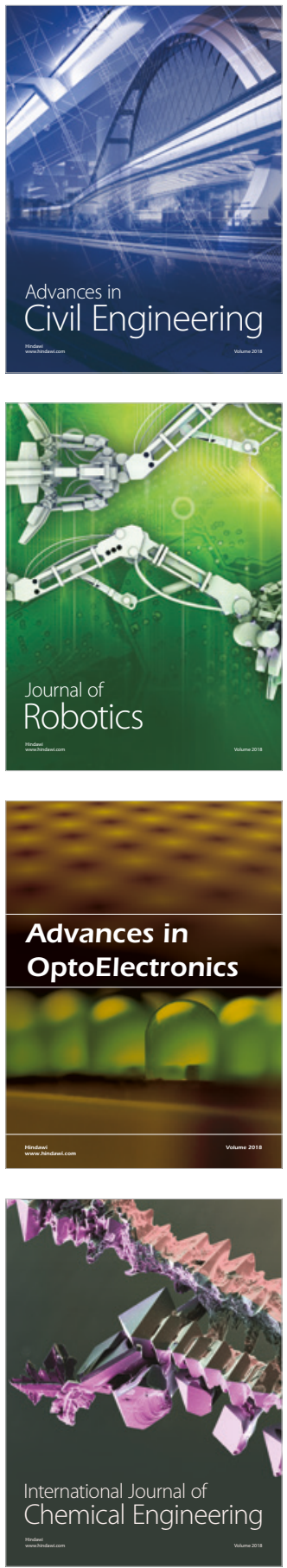

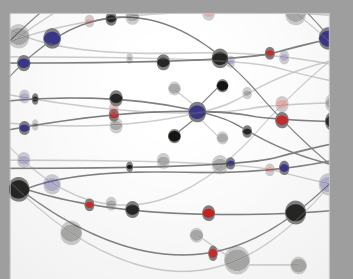

\section{Rotating \\ Machinery}

The Scientific World Journal

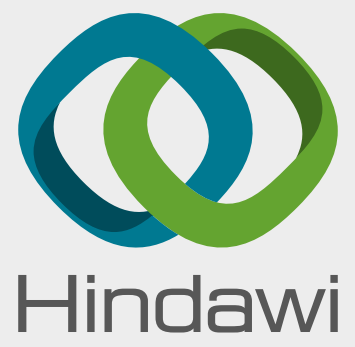

Submit your manuscripts at

www.hindawi.com
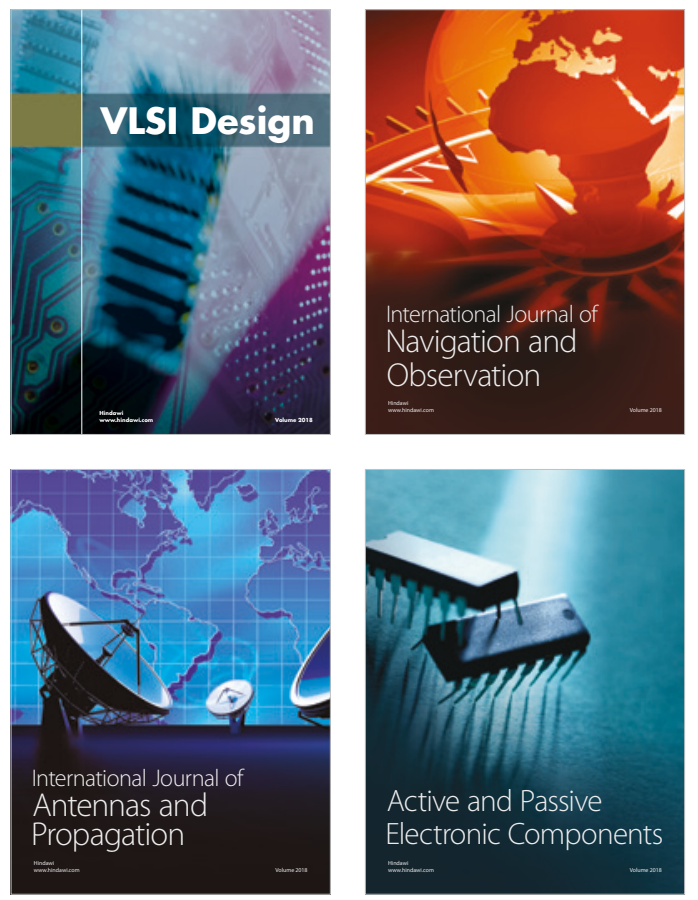
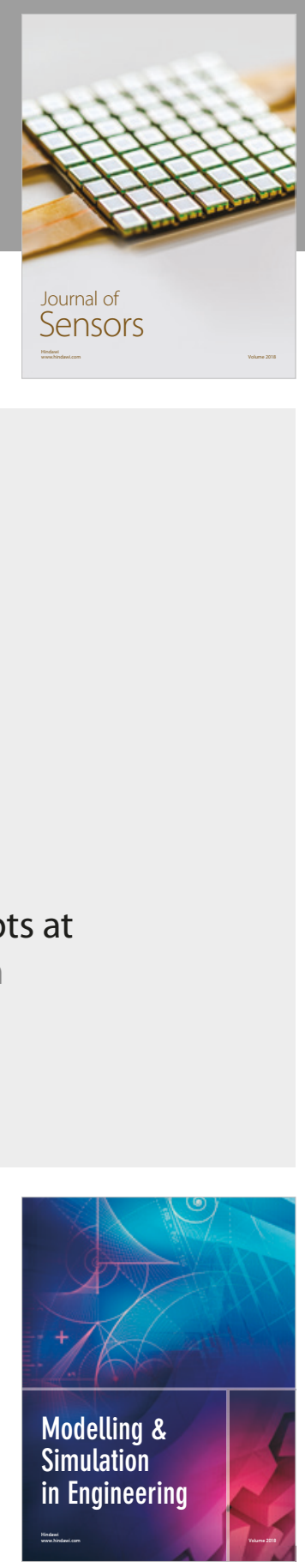

\section{Advances \\ Multimedia}
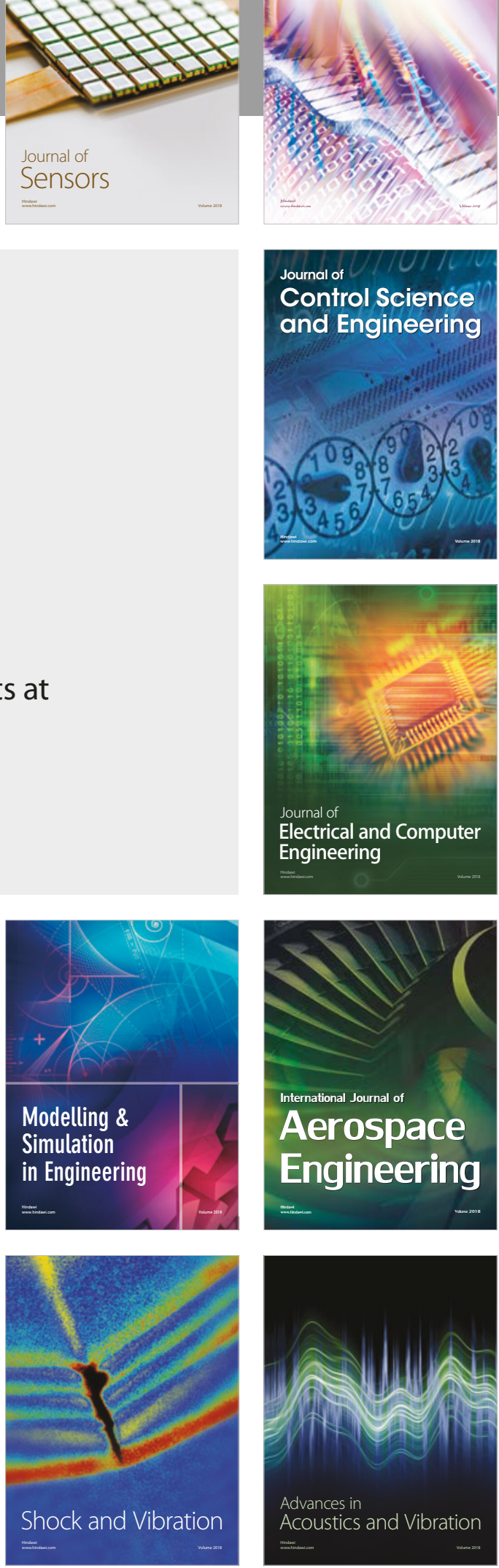